\title{
Transvaginal ultrasound for cervical assessment versus digital vaginal examination during active phase of labour
}

\author{
Nermeen Mohamed Hefila*, Hisham Adel Elfazari
}

Department of Obstetrics and Gynecology, Alexandria University, El Shatby Medical Campus, Alexandria, Egypt

Received: 05 May 2021

Revised: 16 May 2021

Accepted: 19 May 2021

\section{*Correspondence:}

Nermeen Mohamed Hefila,

E-mail: nermeenptsbasem81@gmail.com

Copyright: (C) the author(s), publisher and licensee Medip Academy. This is an open-access article distributed under the terms of the Creative Commons Attribution Non-Commercial License, which permits unrestricted non-commercial use, distribution, and reproduction in any medium, provided the original work is properly cited.

\section{ABSTRACT}

Background: Ultrasound is found to have many uses in obstetrics. As the transvaginal ultrasound is used to examine the cervix in non-pregnant cases, it's also can be used in pregnant cases to detect any cervical changes early in pregnancy, in cases of cervical incompetence, or late in pregnancy in labour to detect progression of cervical changes. Vaginal birth occasionally requires urgent medical intervention to avoid harm to the labouring woman and her baby. Intrapartum ultrasound is a simple technique that improves the understanding of abnormal labour and provides a more scientific basis for assessing labour. In this study, two hundred pregnant women, full term, non-complicated, single tone, cephalic presentation, active stage of labour, attending El-Shatby Maternity University Hospital labour ward were recruited for this study.

Methods: Intrapartum transvaginal ultrasound is done by the obstetrician followed immediately by digital examination done by a second obstetrician in charge to avoid bias.

Results: The results revealed that comparison between mean cervical length measurements assessed by TVUS and digitally revealed statistically significant difference with $\mathrm{p}<0.001$. Also, comparison between mean cervical diameter measurements assessed by TVUS and digitally reveals statistically significant difference with $\mathrm{p}<0.001$.

Conclusions: The TVUS is a suitable alternative to digital examiation in assessing labour progress because it is well accepted, minimal-invasive, less painful and with minimal infectious risks and good tool for estimating labour progress.

Keywords: Intrapartum TVUS, Active labour assessment, Cervical internal OS

\section{INTRODUCTION}

As the obstetrical ultrasound examinations are mainly done to examine fetal growth, abnormalities and wellbeing, now many studies suggest that it's a very reliable and good tool for monitoring progress of labour. Among all experiences of humanity, birth is the most important, considering that the simple objective of every pregnancy is the delivery of a healthy baby to a healthy mother. ${ }^{1}$ Different methods have been used to assess the cervical changes antenatally and to predict which pregnant woman at risk of preterm labour. ${ }^{2}$ Bishop score is the most commonly used because it is simple and most predictive value which is done by vaginal examination. Vaginal digital cervical examination to assess the cervical dilatation, consistency, cervical canal length (effacement) and position is the most commonly used method to decide the successful progress of normal labour process. ${ }^{3}$ Ultrasound is found to be superior to digital cervical examination as it can measure the cervical length which can't be measured accurately by digital examination to determine which case at risk of preterm labour. ${ }^{4}$ Many previous authors had investigate the transabdominal ultrasound to measure cervical length and dilatation. Transvaginal ultrasound is found to be more accurately informative than transabdominal ultrasound as the 
transabdominal ultrasound is done with full bladder which may give less accurate results as this may distort the cervical length and this is not found in transvaginal ultrasound with empty bladder. ${ }^{5,6}$

\section{Aim}

The aim of the study was to compare transvaginal ultrasound and digital examination in cervical assessment at beginning of active phase of labour.

\section{METHODS}

This study was a prospective study from April 2020 till December 2020, 200 pregnant women attending El Shatby University Maternity Hospital were included in this study. They were chosen to be 37 weeks of gestation or more, singleton, normal non-complicated pregnancy with cephalic presentation with true labour pain. All cases were subjected into: history taking, clinical examination (general, abdominal and vaginal) to fulfil selection criteria, ultrasound examination was done by an obstetrician followed immediately by digital examination done by another obstetrician in charge. Transabdominal ultrasound was done first to assess: gestational age, fetal biometry, estimation of fetal weight, fetal presentation, fetal wellbeing (assessment of liquor volume and biophysical profile except NST). And transvaginal ultrasound: all the women underwent one transvaginal scan to assess the following parameters: cervical length in mm, internal OS dilatation in millimetres, amniotic forewater membrane. Then trans labial ultrasound is performed with the probe positioned trans labially aligned sagittal with small lateral movement to assess fetal skull station and forewater membrane bulge (Figure 1). ${ }^{7}$

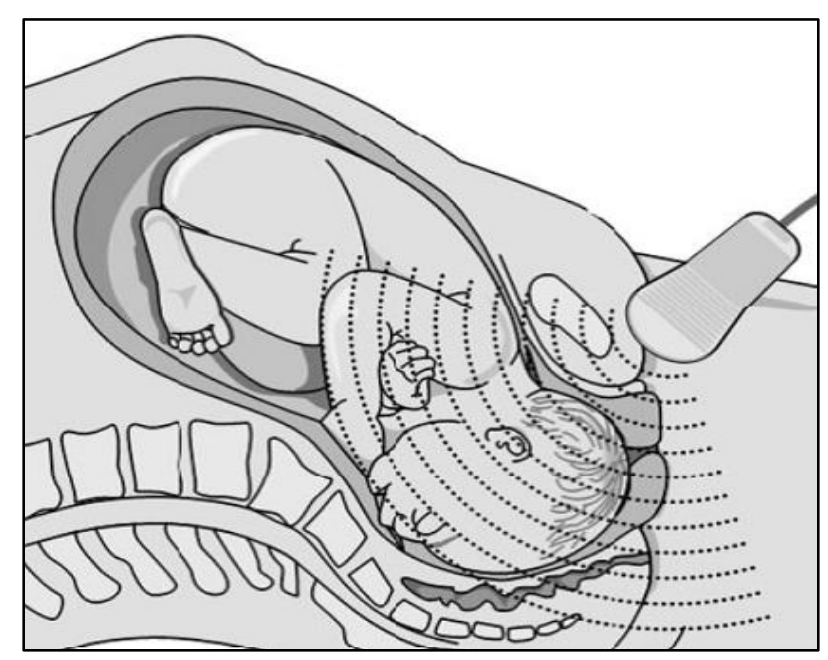

Figure 1: Trans labial ultrasound.

\section{Patients}

Two hundred pregnant women attending El-Shatby Maternity University Hospital labour ward were recruited for this study. A written informed consent is taken from each subject.
The inclusion criteria were: term pregnancy $\geq 37$ weeks, singleton viable pregnancies, cephalic presentation, true labour pain, normal non-complicated pregnancy.

\section{Ethical approval}

This study was approved ethically by ethics committee for the scientific research. All Institutional and National Guidelines for the care and use of animals (insects) were followed.

\section{Statistical analysis of the data}

Data were collected and analysed using IBM SPSS software package version 20.0 (Armonk, NY: IBM Corp).

\section{RESULTS}

\section{Among the 200 pregnant females examined at the active stage of labour}

A total 18 of them ended by caesarean section due to fetal distress or failure of labour progression, 182 of them ended by normal vaginal delivery, 86 were nullipara and 114 were multipara. Table 1 shows distribution of the cases according to the demographic data.

Table 1: Distribution of the cases according to demographic data.

\begin{tabular}{|lll|}
$\begin{array}{l}\text { Age of the } \\
\text { patients (years) }\end{array}$ & $\begin{array}{l}\text { No. of } \\
\text { patients }\end{array}$ & Percentage (\%) \\
\hline$<\mathbf{2 5}$ & 74 & 73.0 \\
\hline $\mathbf{2 0 - 3 0}$ & 116 & 58.0 \\
\hline $\mathbf{3 5 5}$ & 10 & 5.0 \\
\hline Min.-Max. & $17.0-42.0$ & \\
\hline Mean \pm SD & $35.60 \pm 14.75$ & \\
\hline Median & 32.0 & \\
\hline
\end{tabular}

Table 2 shows the distribution of the studied cases according to the measured cervical length by transvaginal ultrasound into three groups $<12 \mathrm{~mm}, 12-18 \mathrm{~mm},>18 \mathrm{~mm}$. Data revealed that about $26 \%$ were $<12 \mathrm{~mm}, 49 \%$ were 12 $18 \mathrm{~mm}$ and $25 \%$ were $>18 \mathrm{~mm}$. The mean for the cervical length is $18.10 \pm 5.09 \mathrm{~mm}$, and the median is 18.35 .

Table 2: Distribution of the studied cases according to Cx length by TVUS $(\mathrm{N}=200)$.

\begin{tabular}{|lll|}
\hline Cx length $(\mathbf{m m})$ & No. of patients & Percentage $(\%)$ \\
\hline $\mathbf{1 2}$ & 52 & 26.0 \\
\hline $\mathbf{1 2 - 1 8}$ & 98 & 49.0 \\
\hline $\mathbf{1 1 8}$ & 50 & 25.0 \\
\hline Min.-Max. & $8.0-27.0 \mathrm{~mm}$ & \\
\hline Mean \pm SD & $18.10 \pm 5.09 \mathrm{~mm}$ \\
\hline Median & $18.35 \mathrm{~mm}$ & \\
\hline
\end{tabular}

Table 3 shows distribution of the studied cases according to cervical effacement by digital examination into three 
groups $50 \%$ or less, $>50-<75 \%, 75 \%$ or more. Data revealed that about $25 \%$ were $50 \%$ effaced, $49 \%$ were $>50-<75 \%$ effaced and $26 \%$ were $75 \%$ or more effaced. The mean for the digitally assessed cervical effacement is $15.44 \pm 3.62 \mathrm{~mm}$, and the median is $16.0 \mathrm{~mm}$.

Table 3: Distribution of the studied cases according to cervical effacement by digital examination $(\mathrm{N}=200)$.

\begin{tabular}{|lll|}
\hline Digital effacement & $\begin{array}{l}\text { No. of } \\
\text { patients }\end{array}$ & Percentage (\%) \\
\hline $\mathbf{5 0}$ or less & 50 & 25.0 \\
\hline $\mathbf{5 0}-<\mathbf{7 5}$ & 98 & 49.0 \\
\hline $\mathbf{7 5}$ or more & 52 & 26.0 \\
\hline Min.-Max. & $10.0-20.0 \mathrm{~mm}$ \\
\hline Mean \pm SD & $15.44 \pm 3.62 \mathrm{~mm}$ \\
\hline Median & $16.0 \mathrm{~mm}$ \\
\hline
\end{tabular}

Table 4 shows relation between $\mathrm{Cx}$ length by transvaginal ultrasound and digital effacement and it reveals; at digital effacement $50 \%$ or less the Cx length measured in $\mathrm{mm}$ were between $(18.0 \mathrm{~mm}-27 \mathrm{~mm})$ and the mean length was
$22.22 \pm 4.02$ and the median length was 19.80. At digital effacement $>50 \%-<75 \%$ the $\mathrm{Cx}$ length measured were between $(9.0 \mathrm{~mm}-25.40 \mathrm{~mm})$ and the mean length was $18.71 \pm 4.41$ and the median length was 19.50 . At digital effacement $75 \%$ or more the Cx length measured were between $(8.0 \mathrm{~mm}-16.40 \mathrm{~mm})$ and the mean length was $13.01 \pm 2.15$ and the median length was 13.0.

Table 4: Relation between digital cervical effacement and $\mathrm{Cx}$ length $(\mathrm{N}=200)$.

\begin{tabular}{|llll|} 
& \multicolumn{3}{l}{ Digital effacement $(\mathbf{m m})$} \\
Cx length & $\mathbf{2 0} \mathbf{~ m m}$ & $\mathbf{1 6} \mathbf{~ m m}$ & $\mathbf{1 0} \mathbf{~ m m}$ \\
& $\mathbf{5 0 \%}$ & $\mathbf{6 0 \%}$ & $\mathbf{7 5 \%}$ \\
\hline Min-Max & $18.0-27.0$ & $9.0-25.40$ & $8.0-16.40$ \\
\hline Mean \pm SD & $22.22 \pm 4.02$ & $18.71 \pm 4.41$ & $13.01 \pm 2.15$ \\
\hline Median & 19.80 & 19.50 & 13.0 \\
\hline
\end{tabular}

Table 5 compares mean cervical length measurements assessed by TVUS and digitally that reveals statistically significant difference with $\mathrm{p}<0.001$.

Table 5: Comparison between digital cervical effacement and $\mathrm{Cx}$ length mean measurements.

\begin{tabular}{|lllll|} 
Comparison parameters & Cx length & Digital effacement $(\mathbf{m m})$ & T value & P value \\
\hline Min-Max & $8.0-27.0$ & $10.0-20.0$ & & $<.091^{*}$ \\
\hline Mean \pm SD & $18.10 \pm 5.09$ & $15.44 \pm 3.62$ & $80.001^{*}$ \\
\hline Median & 18.35 & 16.0 & & \\
\hline
\end{tabular}

$\mathrm{Z}, \mathrm{p}: \mathrm{Z}$ and $\mathrm{p}$ values for Wilcoxon signed ranks test for comparing between. *Statistically significant at $\mathrm{p} \leq 0.05$.

Table 6 shows relation between digital cervical diameter and TVUS Cx internal OS diameter measurement and it reveals: at digital cervical diameter $20 \mathrm{~mm}$ the $\mathrm{Cx}$ internal OS diameters measured were between $(14.2 \mathrm{~mm}-16.0 \mathrm{~mm})$ and the mean diameter was $15.1 \pm 1.3$ and the median length was 15.1. At digital cervical diameter $30 \mathrm{~mm}$ the $\mathrm{Cx}$ internal OS diameters measured were between $(17.3 \mathrm{~mm}-33.0 \mathrm{~mm})$ and the mean diameter was $23.7 \pm 3.5$ and the median length was 23.5. At digital cervical diameter $40 \mathrm{~mm}$ the $\mathrm{Cx}$ internal OS diameters measured were between $(29.0 \mathrm{~mm}-43.0 \mathrm{~mm})$ and the mean diameter was $36.5 \pm 3.7$ and the median length was 36.0. At digital cervical diameter $50 \mathrm{~mm}$ the $\mathrm{Cx}$ internal OS diameters measured were between $(39.0 \mathrm{~mm}-52.0 \mathrm{~mm})$ and the mean diameter was $52.8 \pm 3.3$ and the median length was 45.0. At digital cervical diameter $60 \mathrm{~mm}$ the $\mathrm{Cx}$ internal OS diameters measured were between $(48.0 \mathrm{~mm}-62.0 \mathrm{~mm})$ and the mean diameter was 55.3 \pm 3.1 and the median length was 55.0. At digital cervical diameter $70 \mathrm{~mm}$ the $\mathrm{Cx}$ internal OS diameters measured were between $(62.0 \mathrm{~mm}-71.0 \mathrm{~mm})$ and the mean diameter was $66.5 \pm 2.6$ and the median length was 66.5. At digital cervical diameter $80 \mathrm{~mm}$ the $\mathrm{Cx}$ internal OS diameters measured were between $(78.0 \mathrm{~mm}-79.0 \mathrm{~mm})$ and the mean diameter was $78.5 \pm 0.7$ and the median length was 78.5. At digital cervical diameter $90 \mathrm{~mm}$ the $\mathrm{Cx}$ internal OS diameters measured were between $(88.0 \mathrm{~mm}-93.0 \mathrm{~mm})$ and the mean diameter was $90.5 \pm 1.6$ and the median length was 90.5 .
Table 7 compares mean cervical diameter measurements assessed by TVUS and digitally that reveals statistically significant difference with $\mathrm{p}<0.001$.

The distribution of the examined cases according to condition of the amniotic membrane as examined by digital examination showed that about $37 \%$ had their membrane ruptured and $63 \%$ had membrane intact.

The distribution of the examined cases according to condition of the amniotic membrane as examined by TVUS ultrasound shows that about $42 \%$ were negative for the membrane bulge and $58 \%$ had positive membrane bulge.

Table 8 shows relation between head station assessed digitally and angle of progression by trans labial ultrasound and it reveals statical significance. At station-1 the progression angle measured were between (90-103) and the mean angle was $95.74 \pm 4.56$ and the median angle was 95.45. At station 0 the progression angle measured were between (100.50-135.0) and the mean angle was $112.69 \pm 7.23$ and the median angle was 111.30 . At station 1 the progression angle measured were between (120.0146.0) and the mean angle was $129.33 \pm 6.78$ and the median angle was 127.45 . At station 2 the progression 
angle measured were between (136.30-152.0) and the mean angle was $95.74 \pm 4.56$ and the median angle was 145 .

Table 9 shows the relation between mode of delivery and the progression angle and it illustrates that: in normal vaginal delivery it was noticed that the progression angle was between (90.60-152.0) and the mean was $119.89 \pm 13.69$ and the median was 120.0 , while in caesarean section delivery it was noticed that the progression angle was between (90.0-116.70) and the mean was $105.30 \pm 9.55$ and the median was 105 . The distribution of cases according to the anxiety upon using transvaginal ultrasound technique or doing digital vaginal examination revealed that $11 \%$ of the cases felt anxious with transvaginal ultrasound and about $93 \%$ with digital examination and nearly 7.5 of cases felt with discomfort in both.

Table 6: Relation between digital cervical diameter and the $\mathrm{Cx}$ internal $\mathrm{OS}$ diameters $(\mathrm{N}=200)$.

\begin{tabular}{|lllllllll|}
$\begin{array}{l}\text { Cx internal OS } \\
\text { diameter }(\mathbf{m m})\end{array}$ & $\mathbf{2 0}$ & $\mathbf{3 0}$ & $\mathbf{4 0}$ & $\mathbf{5 0}$ & $\mathbf{6 0}$ & $\mathbf{7 0}$ & $\mathbf{8 0}$ & $\mathbf{9 0}$ \\
\hline Min-Max & $14.2-16.0$ & $17.3-33.0$ & $29.0-43.0$ & $39.0-52.0$ & $48.0-62.0$ & $62.0-71.0$ & $78.0-79.0$ & $88.0-93.0$ \\
\hline Mean \pm SD & $15.1 \pm 1.3$ & $23.7 \pm 3.5$ & $36.5 \pm 3.7$ & $45.1 \pm 3.1$ & $55.3 \pm 3.1$ & $66.5 \pm 2.6$ & $78.5 \pm 0.7$ & $90.5 \pm 1.6$ \\
\hline Median & 15.1 & 23.5 & 36.0 & 45.0 & 55.0 & 66.5 & 78.5 & 90.5 \\
\hline
\end{tabular}

Table 7: Comparison between digital cervical diameter and TVUS Cx internal OS diameter.

\begin{tabular}{|c|c|c|c|c|}
\hline Comparison parameters & Cx IOS diameter (mm) & Digital cervical diameter (mm) & $\mathbf{Z}$ value & P value \\
\hline Min-Max & $14.20-93.0$ & $20.0-90.0$ & & \\
\hline Mean \pm SD & $42.39 \pm 16.03$ & $46.60 \pm 14.75$ & $10.936^{*}$ & $<0.001^{*}$ \\
\hline Median & 40.0 & 40.0 & & \\
\hline
\end{tabular}

$\mathrm{Z}, \mathrm{p}: \mathrm{Z}$ and $\mathrm{p}$ values for Wilcoxon signed ranks test for comparing between. *Statistically significant at $\mathrm{p} \leq 0.05$.

Table 8: Relation between station and angle of progression $(\mathrm{N}=\mathbf{2 0 0})$.

\begin{tabular}{|lllll|}
\hline Angle of progression & Head station & & & 1 $(\mathbf{N}=\mathbf{6 8})$ \\
\hline Min-Max & $\mathbf{- 1}(\mathbf{N}=\mathbf{2 0})$ & $\mathbf{0}(\mathbf{N}=\mathbf{1 0 0})$ & $12)$ & $\mathbf{P}$ value \\
\hline Mean \pm SD & $90.0-103.0$ & $100.50-135.0$ & $120.0-146.0$ & $136.30-152.0$ \\
\hline Median & $95.74 \pm 4.56$ & $112.69 \pm 7.23$ & $129.33 \pm 6.78$ & $144.72 \pm 5.76$ \\
\hline p-1 & 95.45 & 111.30 & 127.45 & 145.0 \\
\hline Sig. between groups & & $<0.001^{*}$ & $<0.001^{*}$ & $<0.001^{*}$ \\
\hline
\end{tabular}

$\mathrm{F}, \mathrm{p}$ : $\mathrm{F}$ and $\mathrm{p}$ values for ANOVA test, Sig. between groups was done using Post Hoc Test (Tukey); $\mathrm{p}-1$ : $\mathrm{p}$ value for comparing between station (-1) and each other stations; $\mathrm{p}_{1}$ : $\mathrm{p}$ value for comparing between station (0) and station (1); $\mathrm{p}_{2}$ : $\mathrm{p}$ value for comparing between station (0) and station (2); $\mathrm{p}_{3}$ : $\mathrm{p}$ value for comparing between station (1) and station (2). *Statistically significant at $\mathrm{p} \leq 0.05$.

Table 9: Relation between mode of delivery and the progression angle.

\begin{tabular}{|c|c|c|c|}
\hline \multirow{2}{*}{$\begin{array}{l}\text { Angle of } \\
\text { progression }\end{array}$} & \multicolumn{2}{|c|}{ Mode of delivery } & \multirow[b]{2}{*}{ P value } \\
\hline & $\begin{array}{l}\text { NVD } \\
(\mathrm{N}=182)\end{array}$ & $\begin{array}{l}\text { CS } \\
(N=18)\end{array}$ & \\
\hline Min-Max & $90.60-152.0$ & $90.0-116.70$ & \multirow{3}{*}{$<0.001^{*}$} \\
\hline Mean \pm SD & $119.89 \pm 13.69$ & $105.30 \pm 9.55$ & \\
\hline Median & 120.0 & 105.0 & \\
\hline
\end{tabular}

*Statistically significant at $\mathrm{p} \leq 0.05$.

\section{DISCUSSION}

Cervical shortening is the most important predictor of the onset of labour. Manual vaginal examination is the most

commonly used method to estimate the cervical length. As the vaginal digital cervical examination is subjective, ultrasound examination is more objective in measuring the cervical length changes. ${ }^{8}$ Many previous studies were about using the transabdominal ultrasound to measure cervical shortening and dilatation with full bladder which distort the cervical canal length. This disadvantage of trans-abdominal ultrasound explains the differing results of various studies of cervical length using the transabdominal approach. ${ }^{9}$

Trans-vaginal ultrasound with empty bladder can provide good visualization of the cervix but it may vary according to parity and gestational age. ${ }^{10}$

This study evaluated a sample of pregnant women (200) presenting at active phase of labour in order to compare digital examination and trans-vaginal ultrasound for the assessment of the cervix. In this study there was a moderate correlation between digital examination and transvaginal ultrasound in the measurement of cervical length $(\mathrm{r}=0.629)$. The mean cervical length measured by ultrasound was $18.10 \pm 5.09 \mathrm{~mm}$ and the median was 18.35 
$\mathrm{mm}$, while the mean of cervical digital effacement was $15.44 \pm 3.62 \mathrm{~mm}$ and the median was $16.0 \mathrm{~mm}$. Lim et al and Sonek et al found a poor correlation between vaginal digital cervical length and ultrasound cervical length with $\mathrm{r}=0.4 .^{11,12}$ Goldberg et al found that the mean cervical lengths by digital examination and vaginal ultrasound were significantly different. ${ }^{13}$ Gabriel et al suggest that when the cervix is unfavourable (Bishop's score $\leq 5$ ), ultrasound examination can measure the supravaginal cervical portion which is important. ${ }^{14}$

Lim et al found that good correlation between digital examination and transvaginal ultrasonography was observed in the measurement of cervical dilatation, in addition the mean cervical dilatation measured digitally is significantly higher than transvaginal ultrasound examination due to manual overstretching of the cervical OS. ${ }^{11}$ However, Eggebo et al found that ultrasound technology is not objective in assessment of cervical dilatation in sagittal view. ${ }^{15}$

The cervix appeared closed in $80 \%$ of the women when assessed by ultrasound, but only $21 \%$ had a closed cervix according to digital assessment. They found that cervical dilatation is the best predictive element of the Bishop score. This difference is attributed to the different sample size which was smaller and the examination that was done in latent phase of labour for induction instead of the active stage. However, in a more recent work by Zimerman et al trans labial 3D ultrasonographic cervical dilatation measurements showed a positive correlation with vaginal digital examinations $\left(\mathrm{r}^{2}=0.609, \mathrm{p}<0.001\right) .{ }^{16}$

Good correlation between digital examination and trans labial ultrasound was obtained in determination of degree of foetal head descent where the relation between head station assessed digitally and progression angle by trans labial ultrasound revealed statical significance $(\mathrm{p}<0.001)$. This agree with Barbera et al that stated a significant association between digital cervical examination and the progression angle by TLUS examination $(\mathrm{p}=0.001) .{ }^{17}$

Moreover, the mean value of the 'angle of progression' was $(119.89 \pm 13.69)$ in cases who delivered vaginally, a value higher than that found in cases delivered by CS (105.30 \pm 9.55$)$. This difference was of high statistical significance $(p<0.001)$. In accordance with the results of the current work, Kalache et al examined the angle of progression measurement and found high correlation between the progression angle and the caesarean delivery. ${ }^{18}$ When the progression angle was 120 , a probability of $90 \%$ for either vaginal delivery or for assisted vaginal delivery.

The data of Barbera et al showed that an angle of at least 120 was always associated with subsequent spontaneous vaginal delivery. ${ }^{17}$ Tutscheck et al concluded that for angle value of $>135,94 \%$ of pregnant women in labour will deliver vaginally. ${ }^{19}$ These results were close to the cut-off values of the current work.
Intrapartum ultrasound seems to correlate well with findings from traditional per vaginum examination. Moreover, it offers easily measurable parameters including cervical length, internal OS diameter and progression angle having an ability not only to detect engagement of fetal head but the likelihood of vaginal delivery as well.

\section{Limitations}

In this study, some limitations were present like admission refusal, PTLP was more common in multiple pregnancies, co-existing diseases with pregnancy like D.M. and hypertensive disorders with pregnancy, case withdrawal and absence of available places in NICU or incubators.

This study resulted in that the mean cervical length measurements by TVUS were greater than average vaginal examination and there was moderate direct correlation between them. Also, it showed that the mean cervical diameter was less than the average of the vaginal examination, and there was good direct correlation between them. The angle of progression was measured and also showed a significant difference between cases of normal delivery and caesarean delivery, where the average angle of progression in the case of normal delivery was greater than caesarean delivery reaching 120 and 105 respectively.

\section{CONCLUSION}

Transvaginal ultrasound converted images for assessment of cervix that ultimately lead to a quantitative assessment of labour. In comparison to bishop`s score transvaginal ultrasound cervical assessment appears to be more objective which allows us to assess progress of active phase of labour. The results strengthen previous studies regarding the feasibility of sonopartogram. It proved to be a suitable alternative in assessing labour because it is well accepted, less-invasive and with minimal infectious risks.

\section{Recommendations}

The availability of TVUS in the labour ward as a complement- not a substitute- for clinical decisionmaking further research should assess the prognostic performance of individual TVUS parameters on larger subgroups of parturient at different stages of the active phase of labour. Intrapartum ultrasound should be used for full assessment of labour progress.

\section{ACKNOWLEDGMENTS}

Authors would like to thank Obstetrics and Gynecology Department, Faculty of Medicine, Alexandria University for their support during study.

\section{Funding: No funding sources \\ Conflict of interest: None declared}

Ethical approval: The study was approved by the Institutional Ethics Committee 


\section{REFERENCES}

1. Iliescu D, Antsaklis P, Paulescu D, Comanescu A, Tudorache S, Antsaklis A, et al. Applications of ultrasound in prelabor and labor. Donald Sch J Ultrasound Obstet Gynecol. 2012;6:257-69.

2. Laughon SK, Zhang J, Troendle J, Sun L, Reddy UM. Using a simplified Bishop score to predict vaginal delivery. Obstet Gynecol. 2011;117(4):805.

3. Kolkman DG, Verhoeven CJ, Brinkhorst SJ, Post JA, Pajkrt E, Opmeer BC, Mol BW. The Bishop score as a predictor of labor induction success: a systematic review. Am J Perinatol. 2013;30(8):625-30.

4. Crane J, Hutchens D. Transvaginal sonographic measurement of cervical length to predict preterm birth in asymptomatic women at increased risk: a systematic review. Ultrasound Obstet Gynecol. 2008;31(5):579-87.

5. Chaudhury K, Ghosh M, Halder A, Senapati S, Chaudhury S. Is transabdominal ultrasound scanning of cervical measurement in mid-trimester pregnancy a useful alternative to transvaginal ultrasound scan?. J Turk Ger Gynecol Assoc. 2013;14(4):225-9.

6. Roh HJ, Ji YI, Jung CH, Jeon GH, Chun S, Cho HJ. Comparison of cervical lengths using transabdominal and transvaginal sonography in midpregnancy. J Ultrasound Med. 2013;32(10):1721-8.

7. Duckelmann AM, Bamberg C, Michaelis SA, Lange J, Nonnenmacher A, Dudenhausen JW, et al. Measurement of fetal head descent using the 'angle of progression' on transperineal ultrasound imaging is reliable regardless of fetal head station or ultrasound expertise. Ultrasound Obstet Gynecol. 2010;35(2):216-22.

8. Berghella V, Palacio M, Ness A, Alfirevic Z, Nicolaides KH, Saccone G. Cervical length screening for prevention of preterm birth in singleton pregnancy with threatened preterm labor: systematic review and meta-analysis of randomized controlled trials using individual patient-level data. Ultrasound Obstet Gynecol. 2017;49(3):322-9.

9. Pandipati S, Combs CA, Fishman A, Lee SY, Mallory K, Ianovich F. Prospective evaluation of a protocol for using transabdominal ultrasound to screen for short cervix. Am J Obstet Gynecol. 2015;213(1):99.

10. Hecht C, Englbrecht M, Rech J, Schmidt S, Araujo E, Engelke K, et al. Additive effect of anti-citrullinated protein antibodies and rheumatoid factor on bone erosions in patients with RA. Ann Rheum Dis. 2015;74(12):2151-6.
11. Lim BH, Mahmood TA, Smith NC, Beat I. A prospective comparative study of transvaginal ultrasonography and digital examination for cervical assessment in the third trimester of pregnancy. J Clin Ultrasound. 1992;20(9):599-603.

12. Sonek JD, Iams JD, Blumenfeld M, Johnson F, Landon M, Gabbe S. Measurement of cervical length in pregnancy: comparison between vaginal ultrasonography and digital examination. Obstet Gynecol. 1990;76(2):172-5.

13. Goldberg J, Newman RB, Rust PF. Interobserver reliability of digital and endovaginal ultrasonographic cervical length measurements. Am J Obstet Gynecol. 1997;177(4):853-8.

14. Gabriel R, Darnaud T, Chalot F, Gonzalez N, Leymarie F, Quereux C. Transvaginal sonography of the uterine cervix prior to labor induction. Ultrasound Obstet Gynecol. 2002;19(3):254-7.

15. Eggebo TM, Okland I, Heien C, Gjessing LK, Romundstad P, Salvesen KA. Can ultrasound measurements replace digitally assessed elements of the Bishop score?. Acta Obstet Gynecol Scand. 2009;88(3):325-31.

16. Zimerman AL, Maymon R, Maymon R, Weinraub Z, Herman A, Tobvin Y. Intrapartum measurement of cervical dilatation using translabial 3-dimensional ultrasonography. Correlation with digital examination and interobserver and intraobserver agreement assessment. J Ultrasound Med. 2009;28:1289-96.

17. Barbera AF, Imani F, Becker T, Lezotte DC, Hobbins JC. Anatomic relationship between the pubic symphysis and ischial spines and its clinical significance in the assessment of fetal head engagement and station during labor. Ultrasound Obstet Gynecol. 2009;33(3):320-5.

18. Barbera AF, Imani F, Becker T, Lezotte DC, Hobbins JC. Anatomic relationship between the pubic symphysis and ischial spines and its clinical significance in the assessment of fetal head engagement and station during labor. Ultrasound Obstet Gynecol. 2009;33(3):320-5.

19. Tutschek B, Braun T, Chantraine F, Henrich W. A study of progress of labour using intrapartum translabial ultrasound, assessing head station, direction, and angle of descent. BJOG. 2011;118(1):62-9.

Cite this article as: Hefila NM, Elfazari HA.

Transvaginal ultrasound for cervical assessment versus digital vaginal examination during active phase of labour. Int J Reprod Contracept Obstet Gynecol 2021;10:2547-52. 